\title{
Sacroiliitis Detected by Magnetic Resonance Imaging in Patients With Systemic Sclerosis
}

\author{
Didem ARSLAN $^{1}{ }^{\oplus}$, İpek TÜRK ${ }^{1}$, Erkan KOZANOĞLU² ${ }^{2}$, Özlem KUDAŞ ${ }^{1}$, \\ Bayram KELLE² ${ }^{2}$, Hakan SAKALLI ${ }^{3}$ (D) \\ ${ }^{1}$ Department of Internal Medicine, Division of Rheumatology, Çukurova University Faculty of Medicine, Adana, Turkey \\ ${ }^{2}$ Department of Physical Medicine and Rehabilitation, Çukurova University Faculty of Medicine, Adana, Turkey \\ ${ }^{3}$ Department of Internal Medicine, Sezar Hospital, Adana, Turkey
}

\begin{abstract}
Objectives: This study aims to evaluate the magnetic resonance imaging (MRI) findings of sacroiliac joints in a selected group of patients with systemic sclerosis (SSc).

Patients and methods: This retrospective study included 30 patients ( 2 males, 28 females; mean age $44.1 \pm 12.5$ years; range, 24 to 70 years) with SSc who underwent MRI of sacroiliac joints. Lesions were defined according to Assessment of SpondyloArthritis International Society (ASAS)/Outcome Measures in Rheumatology MRI group criteria. Clinical features, conventional radiograms of sacroiliac joints, presence of inflammatory back pain human leukocyte antigen B27 (HLA-B27), and C-reactive protein (CRP) levels were extracted from patient records.

Results: Eleven of thirty patients (37\%) revealed sacroiliitis on MRI (five with chronic, three with active sacroiliitis, and three with both active and chronic forms). On conventional radiographic examination, six patients had sacroiliitis (20\%). In all of these six patients, sacroiliitis was also detected on MRI. CRP levels and number of patients with inflammatory back pain were found to be higher in the patients with active sacroiliitis $(p<0.05)$. Seven patients were diagnosed as spondyloarthritis according to ASAS criteria.

Conclusion: Sacroiliitis was detected more frequently by MRI compared to conventional radiographic examination. MRI is suggested to be the preferred method for evaluating sacroiliitis in SSc patients.

Keywords: Magnetic resonance imaging, musculoskeletal involvement, sacroiliitis, spondyloarthritis, systemic sclerosis.
\end{abstract}

Systemic sclerosis (SSc) is a rare autoimmune disease presenting mainly with skin and musculoskeletal symptoms as a result of excessive fibrosis and microangiopathy. Musculoskeletal involvement is one of the most frequent symptoms (24-97\%) particularly in early stages of the disease. ${ }^{1}$ Fatigue and muscle pain are also among the main reasons that reduce the quality of life in SSc patients. Widespread pain is also frequent. ${ }^{2}$ Patients with SSc have many reasons and types of pain; therefore, they may not always be able to discriminate the inflammatory back pain from widespread pain. The latter may also be a concern of spondyloarthritis (SpA). ${ }^{3}$ Contractures and deformities occur mostly in the joints and soft tissues of the hand, which are among the most important reasons of disability. ${ }^{4}$ Joints in the feet, wrist, ankle, knee, and hip may also get involved. ${ }^{5,6}$

In a previous study, which was reported by our group, sacroiliitis was reported to be one of the most frequent joint involvements (23\%)

Received: September 16, 2019 Accepted: December 25, 2019 Published online: January 03, 2020

Correspondence: Didem Arslan, MD. Çukurova Üniversitesi Tıp Fakültesi İç Hastalıkları Anabilim Dalı, Romatoloji Bilim Dalı, 01330 Sarıçam, Adana, Türkiye. Tel: +90530 - 6415880 e-mail: darslantas@cu.edu.tr

Arslan D, Türk I, Kozanoğlu E, Kudaş Ö, Kelle B, Sakallı H. Sacroiliitis Detected by Magnetic Resonance Imaging in Patients With Systemic Sclerosis. Arch Rheumatol 2020;35(4):515-520. 
by conventional radiograms. However, it was suggested that more sophisticated methods such as magnetic resonance imaging (MRI) are required for this evaluation. ${ }^{7}$ Therefore, in this study, we aimed to evaluate the MRI findings of sacroiliac joints in a selected group of patients with SSc.

\section{PATIENTS AND METHODS}

Records of SSc patients admitted to the Department of Internal Medicine, Division of Rheumatology between January 2014 January 2015 were analyzed retrospectively. Of the 157 patients, 30 patients (2 males, 28 females; mean age $44.1 \pm 12.5$ years; range, 24 to 70 years) who underwent MRI of sacroiliac joints were included in the study. The indications of MRI were musculoskeletal pain or high C-reactive protein (CRP). SSc patients were classified according to the American College of Rheumatology (ACR)/ European League Against Rheumatism (EULAR) 2013 criteria. ${ }^{8}$ They were grouped according to the LeRoy criteria as diffuse or limited disease. ${ }^{9}$ The clinical data were collected from patient records. T1 and T2 weighted magnetic resonance images of sacroiliac joints were evaluated according to the Assessment of SpondyloArthritis International Society (ASAS)/ Outcome Measures in Rheumatology MRI group criteria (Figures 1 and 2). ${ }^{10}$ The ASAS scoring method was applied to conventional radiograms. Presence of inflammatory back pain was assessed as defined by ASAS. ${ }^{11}$ Human leukocyte antigen
B27 (HLA-B27) test results (if present) and $\mathrm{CRP}(\mathrm{mg} / \mathrm{L})$ levels were extracted from patient records. The study protocol was approved by the Çukurova University, Faculty of Medicine, Balcalı Hospital Ethics Committee. A written informed consent was obtained from each patient. The study was conducted in accordance with the principles of the Declaration of Helsinki.

\section{Statistical analysis}

Statistical analysis was performed using the PASW version 18.0 program (SPSS Inc., Chicago, IL, USA). Categorical variables were summarized as number and percentage, while continuous variables were summarized as mean \pm standard deviation and median (min-max). Chi-square test was used for comparing the categorical variables between the groups. $P$ values $<0.05$ were considered as statistically significant for all tests.

\section{RESULTS}

Clinical features of the patients are shown in Table 1. Thirty patients (43\%) were taking low-dose steroids (<7.5 mg/day prednisolone), while none of the patients was taking high-dose steroids. Twenty-two patients (73\%) were on hydroxychloroquine, 12 patients (40\%) colchicine, 17 patients (56\%) calcium channel blockers, 11 patients (36\%) angiotensin converting enzyme inhibitor/angiotensin-receptor blocker, six patients (50\%) methotrexate, four patients $(13 \%)$ cyclophosphamide, three patients (10\%)

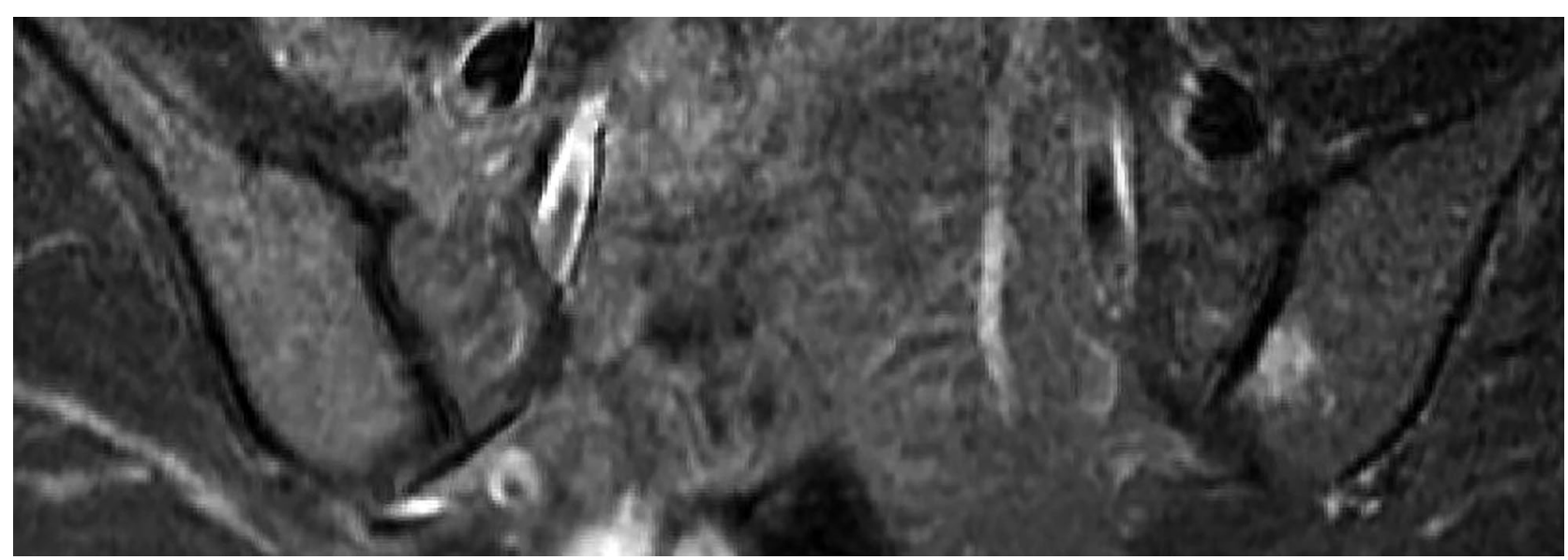

Figure 1. Active sacroiliitis (Sacroiliitic lesions in systemic sclerosis patients in T2 weighted sequences of magnetic resonance imaging). 

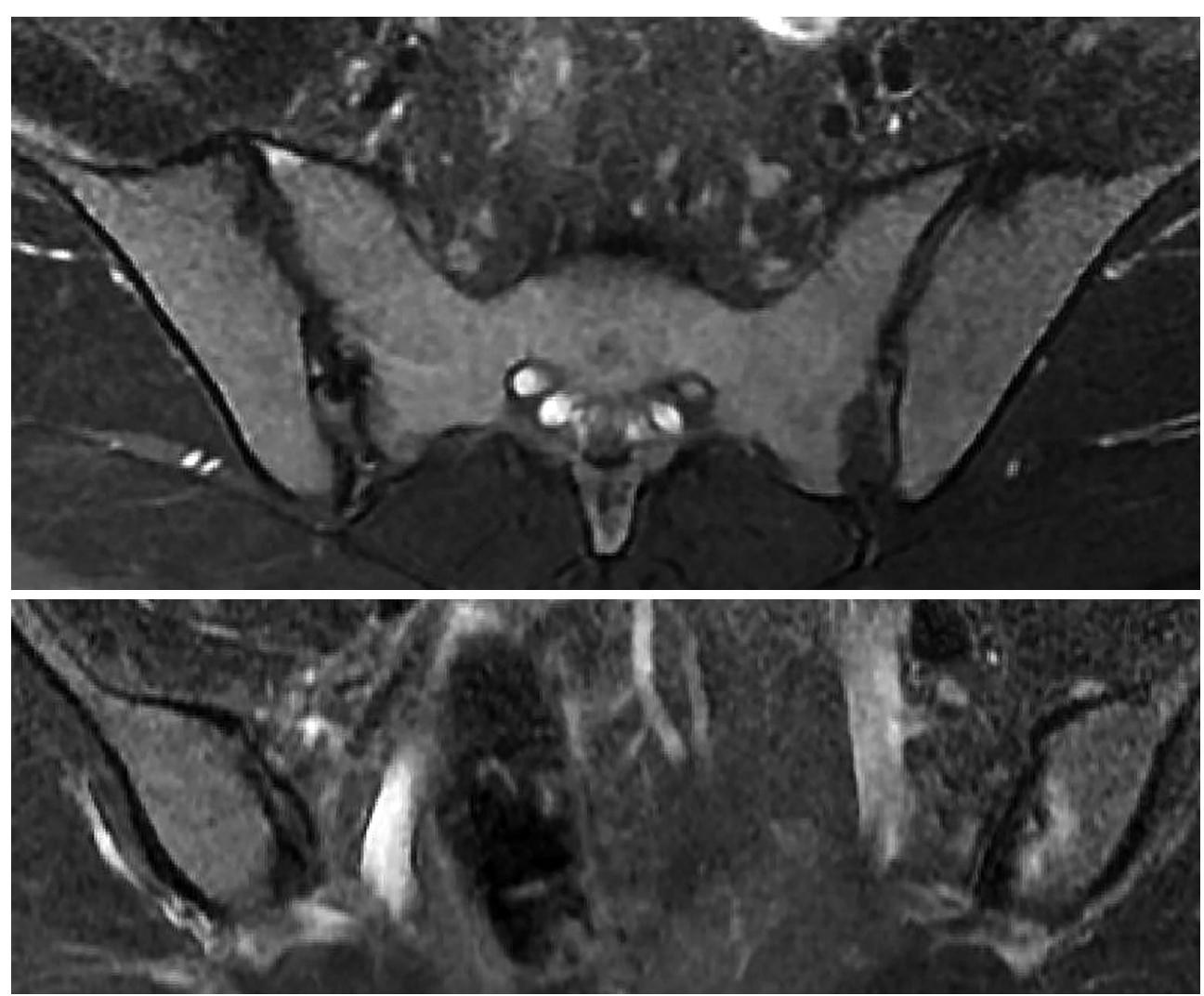

Figure 2. Both active and chronic lesions (Sacroiliitic lesions in systemic sclerosis patients in T2 weighted sequences of magnetic resonance imaging).

mycophenolate mofetil, and five patients (16\%) azathioprine. The time period between CRP test and MRI was $11.9 \pm 5.7$ days. Sacroiliitis was detected by MRI in 11 SSc patients (37\%). Five patients had chronic sacroiliitis, three had active sacroiliitis, and three had both active and chronic forms. For further evaluation, patients were divided into four groups as group 1 (consisting of all patients $\mathrm{n}=30$ ), group 2 (non-sacroiliitis group, $n=19$ ), group 3 (active sacroiliitis group, $n=6$, three patients with active and three patients with both active and chronic lesions), and group 4 (chronic sacroiliitis group, $n=5$, patients with only chronic lesions). Radiographic findings, inflammatory back pain, HLA-B27, and CRP results are shown in Table 2. The clinical features of SSc patients with sacroiliitis on MRI are listed in Table 3. Six patients had diagnostic sacroiliitis on conventional radiograms (20\%). Five patients (17\%), whose conventional radiograms were non-diagnostic, had sacroiliitis detected on MRI. The number of patients with inflammatory back pain in group 3 was five in six patients $(83 \%)$, whereas it was one in 19 patients in group $2(5 \%)$ $(p<0.05)$. CRP levels were significantly higher in group 3 compared to group $2(p<0.05)$. No other clinical or laboratory parameters were found to be

Table 1. Clinical data of study group $(n=30)$

\begin{tabular}{lccc}
\hline & $\mathrm{n}$ & $\%$ & Mean $\pm \mathrm{SD}$ \\
\hline Subgroup & & & \\
$\quad$ Limited & 18 & & \\
$\quad$ Diffuse disease & 12 & & \\
ANA positive & 24 & 80 \\
Anti centromere positive & 8 & 27 \\
Anti Scl-70 positive & 10 & 33 \\
Diagnostic NVC (n=21) & 19 & 90 \\
Organ involvement & & \\
$\quad$ Gastrointestinal & 23 & 76 \\
$\quad$ Lung & 21 & 70 \\
$\quad$ Heart & 19 & 63 \\
$\quad$ Kidney & 0 & 0 & \\
$\quad$ mRodnan & & & 13.8 \pm 6.2 \\
\hline SD: Standard deviation; ANA: Antinuclear antibody; Anti Scl-70: Anti- \\
topoisomerase I after type I topoisomerase target; NVC: Nailfold video \\
capillaroscopy.
\end{tabular}


Table 2. Features of study groups

\begin{tabular}{|c|c|c|c|c|c|c|}
\hline & \multicolumn{2}{|c|}{ All patients $(n=30)$} & \multicolumn{2}{|c|}{ Non-sacroiliitis group $(n=19)$} & \multicolumn{2}{|c|}{ Active sacroiliitis group $(n=6)$} \\
\hline & $\mathrm{n}$ & Mean \pm SD & $\mathrm{n}$ & Mean \pm SD & $\mathrm{n}$ & Mean \pm SD \\
\hline Age (year) & & $44.1 \pm 12.5$ & & $45.1 \pm 13.1$ & & $46.5 \pm 8.5$ \\
\hline $\begin{array}{l}\text { Sex } \\
\quad \text { Male } \\
\text { Female }\end{array}$ & $\begin{array}{c}2 \\
28\end{array}$ & & $\begin{array}{c}2 \\
17\end{array}$ & & $\begin{array}{l}0 \\
6\end{array}$ & \\
\hline Disease duration (year) & & $5.9 \pm 3.9$ & & $6.8 \pm 4.5$ & & $4.3 \pm 1.5$ \\
\hline Inflammatory back pain & $8^{*}$ & & 1 & & $5 \neq$ & \\
\hline Human leukocyte antigen B27 & $\begin{array}{c}4^{* *} \\
\text { (17 studied) }\end{array}$ & & $\begin{array}{c}1 \text { positive } \\
\text { (10 studied) }\end{array}$ & & $\begin{array}{l}2 \text { positive } \\
\text { (4 studied) }\end{array}$ & \\
\hline Diagnostic sacroiliitis radiogram & $6 \dagger$ & & None & & 4 & \\
\hline C-reactive protein $(\mathrm{mg} / \mathrm{L})$ & & $6.7 \pm 3.6$ & & $5.6 \pm 3.0$ & & $10.5 \pm 4.0 \neq$ \\
\hline
\end{tabular}

Table 3. Characteristics of 11 patients with sacroilitis on magnetic resonance imaging

\begin{tabular}{lcccc}
\hline Age, disease subtype & MRI findings & $\begin{array}{c}\text { X-ray findings } \\
\text { (L/R sacroiliac joint) }\end{array}$ & $\begin{array}{c}\text { Inflammatory } \\
\text { back pain }\end{array}$ & HLA-B27 \\
\hline 32 year, limited & Chronic & None & Absent & Negative \\
28 year, limited & Chronic & None & Absent & Negative \\
29 year, diffuse & Chronic & $2 / 3$ & Present & Positive \\
36 year, diffuse & Chronic & None & Absent & Negative \\
62 year, limited & Chronic & $1 / 3$ & Present & Negative \\
33 year, diffuse & Active & None & Absent & Negative \\
42 year, limited & Active & None & Present & Positive \\
53 year, diffuse & Active & $2 / 2$ & Present & Negative \\
48 year, limited & Active + chronic & $2 / 3$ & Present & Negative \\
57 year, limited & Active + chronic & $3 / 4$ & Present & Positive \\
46 year, diffuse & Active + chronic & $2 / 3$ & Present & Negative \\
\hline MRI: Magnetic resonance imaging; HLA-B27: Human leukocyte antigen B27; L: Left; R: Right. & \\
\hline
\end{tabular}

statistically significant between the study groups. When considering all data, seven patients were eligible for being classified as SpA according to ASAS criteria as shown in Table 2. No additional clinical features related to $\mathrm{SpA}$ were reported in these seven patients such as uveitis, psoriasis or inflammatory bowel disease.

\section{DISCUSSION}

Musculoskeletal pain is one of the most disabling complaints for SSc patients. Hands and feet were frequently reported for joint involvement. ${ }^{12}$ As shown before, sacroiliac joints should be considered when evaluating musculoskeletal involvement. According to our knowledge, the first report about sacroiliitis in SSc was conducted in 1847 and cited by Benedek and Rodnan in $1982 .{ }^{13}$ Several case reports were found in the review of the literature. ${ }^{14-18}$ Also, it was reported that sacroiliitis may be present in connective tissue diseases such as Sjögren syndrome, mixed connective tissue disease, and systemic lupus erythematosus. ${ }^{19-21}$

In our previous report, in order to evaluate sacroiliac joint involvement in 57 SSc patients, anteroposterior pelvic radiographs were obtained and graded according to the ASAS scoring method. Sacroiliitis was found in 23\% of the patients; the frequency of inflammatory back pain in SSc patients with sacroiliitis (62\%) was significantly higher in SSc patients without sacroiliitis $(9 \%)(p<0.001) .{ }^{7}$ In the present study, 
sacroiliitis was detected by MRI in 37\% of SSc patients. The rate of patients with inflammatory back pain in active sacroiliitis group was 83\% and was significantly higher than in patients in non-sacroiliitis group $(5 \%) \quad(p<0.05)$. The number of patients with high CRP levels was found to be higher in the active group compared to non-sacroiliitis group $(p<0.05)$. This result is consistent with the higher CRP levels found in connective tissue disease patients with arthritic findings. ${ }^{22}$

In the present study, MRI evaluation is suggested to be superior to conventional radiograms (37\% versus $20 \%$ ). As a general rule, the presence of findings suggesting sacroiliitis on MRI does not show the absolute presence of SpA; sometimes such findings may also be nonspecific.

Sacroiliitis may be a component of joint involvement of SSc or it may be a feature of co-existing SpA. As we know that no underlying physiopathologic link is present between SSc and $\mathrm{SpA}$, the chance of co-existence is relatively low. Kayser et al. ${ }^{17}$ have reported that distinct genes may play roles for susceptibility to two different HLA-associated diseases. These two diseases may co-exist, particularly in patients carrying one or two susceptibility alleles to both diseases. ${ }^{18}$ Further genetic studies may help to clarify the underlying mechanism of this co-existence.

The limitations of this study are its retrospective design, absence of some data such as HLA-B27, and the relatively small sample size although SSc is a rare disease.

In conclusion, when evaluating sacroiliac joints of SSc patients, MRI is recommended to be the preferred method particularly for patients with high CRP and/or musculoskeletal pain. Further prospective studies should be designed to evaluate the clinical and laboratory correlations of sacroiliac involvement in larger SSc patient groups.

\section{Declaration of conflicting interests}

The authors declared no conflicts of interest with respect to the authorship and/or publication of this article.

\section{Funding}

The authors received no financial support for the research and/or authorship of this article.

\section{REFERENCES}

1. Jacques T, Sudol-Szopinska I, Larkman N, O'Connor P, Cotten A. Musculoskeletal Manifestations of Non-RA Connective Tissue Diseases: Scleroderma, Systemic Lupus Erythematosus, Still's Disease, Dermatomyositis/Polymyositis, Sjögren's Syndrome, and Mixed Connective Tissue Disease. Semin Musculoskelet Radiol 2018;22:166-79.

2. Di Franco M, Bazzichi L, Casale R, Sarzi-Puttini P, Atzeni F. Pain in systemic connective tissue diseases. Best Pract Res Clin Rheumatol 2015;29:53-62.

3. Atzeni F, Boccassini L, Di Franco M, Alciati A, Marsico A, Cazzola M, et al. Chronic widespread pain in spondyloarthritis. Reumatismo 2014;66:28-32.

4. Schnitzer M, Hudson M, Baron M, Steele R; Canadian Scleroderma Research Group. Disability in systemic sclerosis -- a longitudinal observational study. J Rheumatol 2011;38:685-92.

5. Randone SB, Guiducci S, Cerinic MM. Musculoskeletal involvement in systemic sclerosis. Best Pract Res Clin Rheumatol 2008;22:339-50.

6. Schmeiser T, Pons-Kühnemann J, Özden F, MüllerLadner U, Dinser R. Arthritis in patients with systemic sclerosis. Eur J Intern Med 2012;23:e25-9.

7. Arslan Tas D, Ylldız F, Sakallı H, Kelle B, Ballı T, Erken E. Sacroiliac joint involvement in systemic sclerosis. Int J Rheum Dis 2015;18:84-90.

8. van den Hoogen F, Khanna D, Fransen J, Johnson SR, Baron M, Tyndall A, et al. 2013 classification criteria for systemic sclerosis: an American College of Rheumatology/European League against Rheumatism collaborative initiative. Arthritis Rheum 2013;65:2737-47.

9. LeRoy EC, Black C, Fleischmajer R, Jablonska S, Krieg T, Medsger TA Jr, et al. Scleroderma (systemic sclerosis): classification, subsets and pathogenesis. J Rheumatol 1988;15:202-5.

10. Hermann KG, Baraliakos X, van der Heijde DM, Jurik AG, Landewé R, Marzo-Ortega $\mathrm{H}$, et al. Descriptions of spinal MRI lesions and definition of a positive MRI of the spine in axial spondyloarthritis: a consensual approach by the ASAS/OMERACT MRI study group. Ann Rheum Dis 2012;71:1278-88.

11. Sieper J, van der Heijde D, Landewé R, Brandt J, Burgos-Vagas R, Collantes-Estevez E, et al. New criteria for inflammatory back pain in patients with chronic back pain: a real patient exercise by experts from the Assessment of SpondyloArthritis international Society (ASAS). Ann Rheum Dis 2009;68:784-8.

12. Arslan Tas D, Erken E, Sakalli H, Yucel AE. Evaluating hand in systemic sclerosis. Rheumatol Int 2012;32:3581-6.

13. Benedek TG, Rodnan GP. The early history and nomenclature of scleroderma and of its differentiation from sclerema neonatorum and scleroedema. Semin Arthritis Rheum 1982;12:52-67. 
14. O'Hare JA, Murnaghan D. Ankylosing spondylitis, lymphoma and scleroderma--a unique conjunction. Ir J Med Sci 1982;151:351-2.

15. Witt $P$, Thomas E. Transfer dysphagia in a patient with the rare combination of scleroderma and ankylosing spondylitis. J Natl Med Assoc 1987;79:993-4.

16. Pham T, Daumen-Legre V, Lafforgue P. Concomitant spondylarthropathy and CREST syndrome. Clin Exp Rheumatol 1999;17:754.

17. Kayser C, Alvarenga MC, Neves AS, Gerbase-De Lima M, Andrade LE. Severe ankylosing spondylitis and diffuse systemic sclerosis: case report of a genetic trap. Scand J Rheumatol 2005;34:145-7.

18. Soledade CS, Sampaio-Barros PD, Samara AM, Marques-Neto JF. Unusual association of systemic sclerosis and ankylosing spondylitis. Clin Rheumatol 2005;24:652-4.
19. Eren R, Can M, Alibaz-Öner F, Yilmaz-Oner S, Yilmazer B, Cefle A, et al. Prevalence of inflammatory back pain and radiologic sacroiliitis is increased in patients with primary Sjögren's syndrome. Pan Afr Med J 2018;30:98.

20. Lee JY, Chang HK, Kim SK. Successful etanercept therapy for refractory sacroiliitis in a patient with ankylosing spondylitis and mixed connective tissue disease. Yonsei Med J 2008;49:159-62.

21. Kappes J, Schoepflin G, Bardana E, Bennet R. Lupoid sarcoarthropathy: a previously undescribed association. Arthritis Rheum 1980;23:699-700.

22. Avouac J, Walker U, Tyndall A, Kahan A, MatucciCerinic M, Allanore Y; EUSTAR, et al. Characteristics of joint involvement and relationships with systemic inflammation in systemic sclerosis: results from the EULAR Scleroderma Trial and Research Group (EUSTAR) database. J Rheumatol 2010;37:1488-501. 